\title{
Kesalahan siswa SMA dalam memecahkan masalah pada materi Hukum
}

\author{
Newton \\ Dheka Januarifin*, Parno, Arif Hidayat \\ Program Studi S2 Pendidikan Fisika Universitas Negeri Malang, Indonesia \\ *Penulis korespondensi, e-mail: decajanu49@gmail.com
}

\begin{abstract}
This study described students mistake on solving newton's law problems. The subjects were 60 students of high school in 11th grade. This study used survey method with data collection technique was test. Test consisted of 10 items about the description of Newton's law (cronbach alpha 0.638). The results showed that many students mistake on solving problems about 1 st Newton's Law, 2nd Newton's law, 3rd Newton's law and concept of friction. Students just rememberred the mathematical equations of Newton's law without understanding the physical meaning. It was advisable to conduct further research as an effort to reduce students' mistakes, one of them is through learning that involves students participating on problem solving and given assistance so that students can do problem solving independently.
\end{abstract}

Keywords: newton's law, problem solving, student's mistake

\begin{abstract}
Abstrak: Penelitian ini mendeskripsikan kesalahan siswa dalam memecahkan masalah hukum newton. Subyek penelitian siswa kelas XI SMA berjumlah 60. Penelitian menggunakan meteode survey dengan teknik pengumpulan data yaitu tes. Tes terdiri atas 10 butir soal uraian materi hukum Newton (cronbach alpha 0,638). Hasil penelitian menunjukkan bahwa siswa banyak mengalami kesalahan dalam memecahkan masalah hukum I Newton, hukum II Newton, hukum III Newton dan konsep gaya gesek. Faktor penyebab kesalahan tersebut adalah karena siswa kurang memahami hukum I Newton, hukum II Newton, hukum III Newton dan konsep gaya gesek. Siswa hanya hanya menghafal persamaan matematis hukum Newton tanpa memahami makna fisis. Disarankan untuk melakukan penelitian lebih lanjut sebagai upaya mengurangi kesalahan siswa, salah satunya melaui pembelajaran yang melibatkan siswa ikut serta dalam pemecahan masalah dan diberi bantuan agar siswa dapat melakukan pemecahan masalah secara mandiri.
\end{abstract}

Kata kunci: Hukum Newton; kemampuan pemecahan masalah; kesalahan siswa

\section{Pendahuluan}

Konsep hukum Newton Merupakan konsep yang erat kaitannya dengan kehidupan sehari- hari. Konsep hukum Newton berhubungan langsung dengan beraneka ragam fenomena alam yang berkaitan dengan kehidupan sehari-hari (serway \& Jewet, 2010). Konsep hukum Newton menjelaskan tentang posisi, waktu, kecepatan dan percepatan (Knight, 2004). Konsep hukum Newton merupakan konsep penting karena konsep tersebut dapat menjelaskan fenomena alam yang berkaitan dengan gerak (Astrina, 2014). Konsep-konsep dalam hukum Newton menuntut siswa berpikir secara abstrak. Selain itu, dalam memahami hukum Newton siswa diharapakan dapat menganalisis permasalahan yang diberikan.

How to Cite:

Januarifin, D., Parno, P., \& Hidayat, A. (2018). Kesalahan siswa SMA dalam memecahkan masalah pada materi Hukum Newton. Momentum: Physics Education Journal, 2(2).

https://doi.org/10.21067/mpej.v1i1.2292

This is an open access article under the CC BY license (http://creativecommons.org/licenses/by-nc-nd/4.0/) https://doi.org/10.21067/mpej.v1i1.2292 
Namun kenyataannya siswa mengalami kesulitan dalam memahami konsep hukum Newton yang berakibat siswa tidak dapat menyelesaikan permasalahan yang diberikan. Penelitian yang dilakukan Nurcahyo (2017) menyatakan kurangnya pemahaman konsep, berdampak pada kesulitan dalam memecahkan masalah pada materi hukum Newton. Siswa yang handal memecahkan masalah adalah siswa yang memahami konsep yang mendasari permasalah (Lin, D., 2011). Sebagian besar siswa tidak memiliki pemahaman konsep yang baik. Siswa cenderung hanya menghafal bunyi hukum Newton dan tidak memahami makna fisis dari hukum tersebut (Malichatin, 2013). Siswa hanya mengahafal persamaan matematis tanpa memahami makna fisis, akibatnya siswa kesulitan dalam membayangkan gaya-gaya yang bekerja pada suatu benda (Nun, 2014). Siswa memiliki konsep yang berbeda dengan konsep para ahli (Radovanoniḉ2 \& Sliško 2013). Hal tersebut berdapak pada kurangnya kemampuan pemecahan masalah dan menyebabkan kesalahan dalam mengerjakan permasalah hukum Newton.

Kemampuan pemecahan masalah merupakan hal penting bagi siswa. Kemampuan pemecahan masalah dianggap sebagai komptensi inti abd 21, pemecahan masalah semakin disorot oleh para peneliti dan pendidik untuk mencapai tujuan pendidikan kontemporer (Care, Scoular, \& Griffin, 2016 ; Lin, Duh, Li, Wang, \& Tsai, 2013; Lin, Hou, Wu, \& Chang, 2014). Kemampuan pemecahan merupakan hal yang penting karena sebagai elemen dasar yang menunjang siswa untuk sains (Ibrahim \& Rebello, 2012). Kemampuan pemecahan masalah dapat membantu siswa dalam menghadapi situasi baru (Hu \& Rebello, 2013). Kemampaun pemecahan masalah bisa menjadi pengaplikasian pengetahuan sains (Ibrahim \& Rebello, 2012).

Fakta dilapangan menunjukkan bahwa banyak siswa yang belum memiliki kemampuan pemecahan masalah yang baik. Hasil penelitian yang dilakukan Susiana (2017) pada 28 siswa kelas X SMA menunjukkan bahwa secara keseluruhan siswa mengalami kesulitan dalam pemecahan masalah dan memiliki kemampuan pemecahan masalah yang rendah. Kemampuan siswa dalam menuliskan informasi penting dari soal $28,6 \%$, kemampuan siswa menentukan prinsip fisika $0 \%$, kemampuan menyajikan langkah-langkah dengan menggunakan pendekatan fisika 43,2\%, kemampuan siswa dalam perhitungan matematis $41,1 \%$, dan kemampuan siswa membuat solusi jawaban yang logis 10,7\%. Hal tersebut mengakibatkan siswa sering melakukan kesalahan dalam mengerjakan soal pemecahan masalah. Selain itu banyak faktor yang membuat siswa kesulitan dalam memecahkan masalah. Siswa memiliki konsep yang berbeda dengan konsep pada ahli sehingga siswa kesulitan dalam memecahkan masalah (Planinic, Boone, Krsnik, \& Beilfuss, 2006). Tidak ada siswa yang melakukan analisis kualitatif dan menemukan konsep yang mendasari permasalahan (Zewdie, 2014). Siswa langsung menuliskan persamaan matematis dan membandingkan dengan permasalahan yang ada pada contoh soal (Eunsook \& Sung-Jae, 2002). Menebak rumus yang digunakan dengan mengahafal contoh soal yang telah dikerjakan sebelumnya. Doctor, dkk (2015) menyatakan bahwa menebak rumus dan memanipulasi persamaan tidak dapat meningkatkan kemampuan pemecahan masalah. Berdasarkan fakta tersebut, artikel ini berupaya untuk mengungkap kesalahan-kesalahan yang dialami siswa dalam memecahkan masalah pada hukum I Newton, II Newton dan III Newton serta memecahkan masalah konsep gaya gesek.

\section{Metode}

Penelitian dilaksanakan di SMAN An-Nur Malang tahun ajaran 2017/2018. Metode pengumpulan data menggunakan metode survey dengan teknik pengumpulan data berupa tes dan wawancara. Respon penelitian yaitu siswa kelas XI IPA 2 dan IPA 3 yang terdiri dari 60 siswa.

Instrumen pengumpualan data berupa tes dan pedoman wawancara. Tes terdiri dari 10 butir soal uraian pemecahan masalah materi hukum Newton dengan cronbach alpha 0,638 . Wawancara digunakan untuk mengetahui faktor-faktor yang mempengaruhi kesalah siswa. Subyek wawancara yaitu 6 siswa yang dipilih berdasarkan nilai tes dengan ketentuan sebagai berikut: 2 siswa dengan nilai paling tinggi, 2 siswa dengan nilai sedang dan 2 siswa dengan nilai rendah. 


\section{Hasil dan Pembahasan}

\subsection{Kesalahan Siswa dalam Memecahakan Masalah pada Hukum I Newton}

Butir soal yang digunakan menunjukkan pemecahan masalah pada hukum I Newton disajikan pada Gambar 1. Terdiri dari dua soal yaitu soal nomor 1 dan nomor 2.

1. Risky membeli sepeda motor baru di dealer Yamaha. Karena masih baru Rizky tidak boleh melaju dengan kecepatan tinggi. Pada lintasan lurus Rizky melihat speedometer menunjukkan $50 \mathrm{~km} / \mathrm{jam}$, jika Rizky ingin memaksimalkan bahan bakar, namun tidak mau kecepatannya berkurang apa yang harus Rizky lakukan? Dan berapakah lelajuan Rizky setelah 10 detik?

2. Andi meletakkan kotak bermassa $20 \mathrm{~kg}$ di ujung prosotan yang licin dengan kemiringan $30^{\circ}$. Kemudian Andi memberikan gaya untuk menahan balok tersebut agar tidak meluncur ke bawah. Jika Andi ingin memberikan gaya sekecil mungkin untuk menahan balok tersebut, berapakah gaya minimal yang diberikan agar balok tidak meluncur ke bawah? (perceptan gravitasi $\mathrm{g}=10 \mathrm{~m} / \mathrm{s}^{2}$ )

Gambar 1. Soal Pemecahan Masalah Hukum I Newton

Soal nomor 1 menunjukan orang yang mengendarai mobil dengan kelajuan konstan 50 km/jam. Siswa diminta untuk memberikan solusi agar orang tersebut dapat memaksimalkan bahan bakar, namun tidak mengalami penurunan kecepatan dan ditanyakan berapakah kecepatan saat $\mathrm{t}=10$ sekon. Dengan ketentuan jika pedal gas diinjak terus menerus gaya kecepatan akan semakin meningkat karena ada gaya dorong kedepan dan jika pedal gas di lepaskan kecepatan akan menurun karena aga gaya hambat yang dialami mobil mobil yaitu gaya gesek.

Sebanyak 40 siswa kecepatan pada saat $\mathrm{t}=10$ sekon adalah $50 \mathrm{~km} / \mathrm{jam}$ namun tidak memberikan solusi permasalahan. siwa yang menjawab demikian masih belum memahami hukum I Newton sehingga siswa bingung antara konsep benda yang bergerak dengan kecepatan konstan dan hukum I Newton. Sebanyak 18 siswa hanya menuliskan besaran yang ada pada soal. Siswa yang menjawab demikian masih belum memahami hukum I Newton sehingga siswa tidak tahu apa yang harus mereka kerjakan untuk menyelesaikan masalah tersebut. Sebanyak 2 siswa menjawab menekan pedal gas dengan konstan. Karena mobil bergerak dengan kecepatan konstan mobil tidak mengalami percepatan sehingga kecepatan pada saat $\mathrm{t}=10$ sekon adalah tetap yaitu $50 \mathrm{~km} / \mathrm{jam}$. Siswa yang menjawab demikian menunjukan siswa sudah memahami hukum I Newton dan dapat menyelesaikan masalah.

Soal nomor 2 menunjukkan balok bermassa 20kg diletakan pada bidang miring yang licin dengan sudut kemiringan $\mathbf{3 0}^{\mathbf{0}}$. Siswa diminta menentukan besar gaya agar balok tersebut tidak meluncur kebawah. Sebanyak 31 siswa menjawab dengan menuliskan besaran-besaran yang ada pada soal. Siswa yang menjawab demikian masih belum memahami hukum I Newton dan masih belum bisa menyelesaikan masalah sehingga siswa tidak bisa menyelesaikan masalah, Sebanyak 21 siswa menjawab gaya yang diberikan adalah $\mathrm{mg} \sin \theta$ namun tidak membuat gambar gaya-gaya yang bekerja pada balok tersebut. Siswa yang menjawab demikian menunjukkan siswa sudah memahani hukum I Newton namun siswa masih belum terbiasa mengidentifikasi gaya-gaya yang bekerja pada benda. Sebanyak 1 siswa menjawab gaya yang diberikan adalah $\mathrm{mg} \cos \theta$. Siswa yang menjawab demikian sudah memahami hukum I Newton namun masih bingung dalam menentukan sudut yang digunakan. Sebanyak 7 siswa menjawab gaya yang diberikan adalah $\mathrm{mg} \sin \theta$ dan mengambarkan gaya-gaya yang bekerja pada benda. Siswa yang menjawab demikian menunjukkan siswa sudah memahami hukum I Newton dan dapat menyelesaikan masalah.

Berdasarkan analisis data dapat diketahui siswa masih belum mamahami hukum I Newton untuk menyelesaikan masalah tersebut. Siswa tidak tahu harus menggunakan persamaan apa yang dapat digunakan untuk menyelesaikan masalah tersebut. siswa. Ketidaktahuan siswa tersebut terjadi karena siswa 
hanya mengahafal persamaan hukum I Newton tanpa memahami makna fisis dari persamaan hukum I Newton sehingga pemahaman siswa menjadi kurang. Kurangnya pemahaman konsep yang dimiliki siswa membuat siswa mengalami kesalahan dalam dalam memecahkan masalah. Pemahaman konsep yang baik merupakakan dasar dari pemecahan masalah (Lin, D., 2011). Selain itu untuk dapat memecahkan masalah siswa harus memiliki pemahaman konsep yang baik dan dapat mengoperasikan persamaan matematis (Kuo, Hull, Gupta, \& Elby, 2013).

Siswa mengalami peningkatan ketika mengerjakan soal nomor 2. Bentuk soal nomor 2 lebih lebih mirip dengan contoh-contoh soal yang dikerjakan siswa. Hal tersebut menyebabkan siswa lebih memahami soal dan dan mudah mengerjakan soal pemecahan masalah. Hal tersebut menunjukkan bahwa siswa masih belum terbiasa mengerjakan soal soal pemecahan masalah. Siswa cenderung lebih mudah mengerjakan soal yang mirip dengan contoh soal daripada soal baru yang belum pernah dikerjakan.

Berdasarkan hasil wawancara menunjukkan siswa kurang memahami hukum I Newton. Siswa memahami hukum I Newton secara matematis (menghafal rumus). Selain itu siswa terbiasa mengerjakan latihan soal. Hal tersebut berdampak siswa hanya bisa mengerjakan soal yang mirip dengan contoh soal.

\subsection{Kesalahan Siswa dalam Memecahakan Masalah pada Hukum II Newton}

Butir soal yang digunakan untuk menunjukkan kemampuan pemecahan masalah pada hukum II Newton disajikan pada Gambar 2. Terdiri dari 4 soal yaitu soal nomor 3, 4, 5 dan 6.

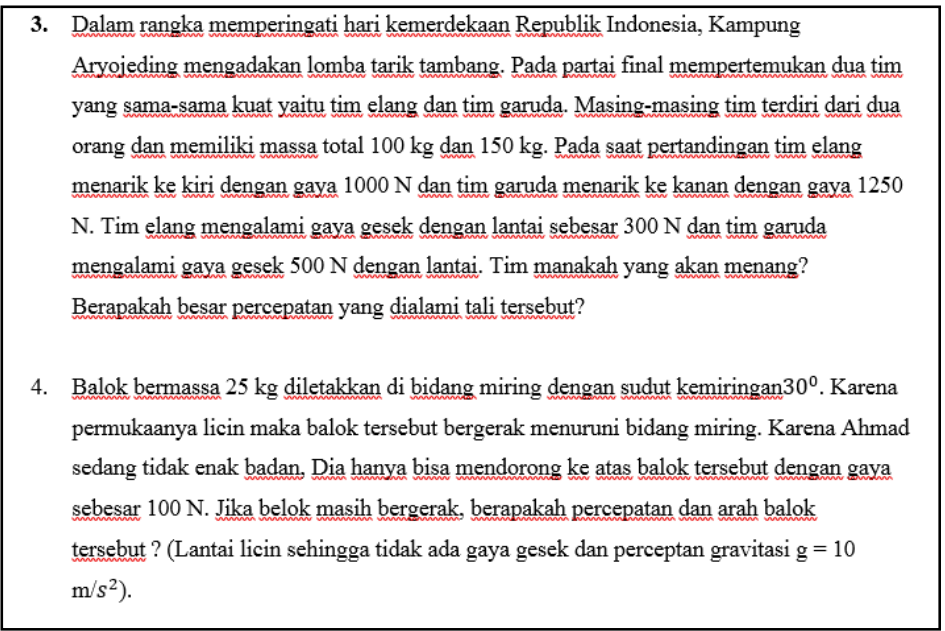

Gambar 2. Soal Pemecahan Masalah Hukum II Newton

Soal nomor 3 menunjukkan fenomena lomba tarik tambang dimana di kampung Aryojeding. Siswa diminta untuk menentukan tim manakah yang akan menang. Sebanyak 20 siswa hanya menuliskan besaranbesaran yang ada pada soal tanpa menyelesaikan masalah. Siswa yang menjawab demikin belum terlatih mengerjakan soal pemecahan masalah, sehingga siswa tidak bisa menyelesaikan masalah. Sebanyak 2 siswa menjawab $\sum \mathrm{F}=$ ma namun tidak menyelesaikan masalah. Siswa yang menjawab demikian menunjukan siswa sudah memahami bahwa soal akan diselesaikan dengan hukum II Newton, namun siswa masih belum bisa menyelesaikan permasalahan. sebanyak 38 siswa menjawab yang menang adalah tim garuda. Siswa yang menjawab demikian sudah memahami hukum II Newton dan dapat menyelesaikan permasalahan.

Soal nomor 4 menunjukkan balok bermassa $25 \mathrm{~kg}$ yang diletakkan pada bidang miring licin dengan sudut kemiringan $\mathbf{3 0}^{\mathbf{0}}$. Kemudian diberi gaya untuk menahan balok tersebut sebesar $100 \mathrm{~N}$. Siswa diminta untuk menetukan apakah benda masih bergerak setelah diberi gaya, dan jika bergerak berapakah percepatan yang dialami balok tersebut. Sebanyak 26 siswa hanya menuliskan besaran yang ada pada soal. Siswa yang menjawab demikian belum mamahami hukum II Newton sehingga siswa tidak tahu bagai cara menyelesaikan permasalahan. Sebanyak 25 siswa menjawab percepatan yang dialami oleh balok adalah $5 \mathrm{~m} / \mathrm{s}^{2}$ tanpa mengambarkan gaya-gaya yang bekerja pada balok tersebut. Siswa yang menjawab demikan sudah 
memahami dan dapat menyelesaikan masalah hukum II Newton namun masih belum terbiasa mengidentfikasi gaya-gaya yang bekerja pada benda. Sebanyak 9 siswa menjawab balok tetap bergerak dengan percepatan $5 \mathrm{~m} / \mathrm{s}^{2}$ dan siswa mengidentifikasi gaya yang bekerja pada balok. Siswa yang menjawab demikian sudah memahami dan bisa menyelesaikan masalah hukum II Newton dan sudah terbiasa mengidentifikasi gaya-gaya yang bekerja pada balok.

Soal nomor 5 dan 6 menunjukan orang yang menarik lemari dan kulka secara bersaman dengan cara diikat. Siswa diminta untuk menentukan besar tegangan tali agar tali tidak putus. Sebanyak 32 siswa menjawab dengan menuliskan besaran yang ada pada soal. Siswa yang menjawab demikian belum mamahami dan belum bisa menyelesaikan permasalahan hukum Newton. Sebanyak 19 siswa menjawab percepatan yang dialami benda. Siswa yang menjawab demikian sudah memahami bahawa soal dapat diselesaikan dengan hukum II Newton, namun masih bingung menghubungkan tegangan tali dengan percepatan yang sudah diperoleh. Sebanyak 9 siswa menjawab $20 \mathrm{~N}$ dan mengidentifikasi gaya-gaya yang bekerja. Siswa yang menjawab demikian sudah memahami dan sudah bisa menyelesaikan masalah hukum II Newton.

Berdasarkan analisis data dapat diketahui bahawa siswa masih belum memahami hukum II Newton untuk menyelesaikan masalah tersebut. Siswa kesulitan menghubungkan besaran yang ada pada soal dengan persamaan hukum II Newton. Siswa hanya menuliskan besaran-besaran yang ada pada soal. Selain itu ada beberapa siswa yang menuliskan persamaan hukum II Newton tetapi tidak dapat menyelesaikan permasalahan. Menebak rumus tidak akan meningkatkan kemampuan pemecahan masalah (Doctor, 2015). Hal tersebut terjadi karena siswa hanya mengahfal persamaan hukum II Newton.

Selain itu siswa tidak mengidentifikasi gaya-gaya yang bekerja pada benda. Hal tersebut menyebabkan siswa tidak bisa menyelesaikan masalah. Padahal mengidentifikasi gaya-gaya yang bekerja adalah hal yang harus dilakukan siswa untuk menyelesaiakan masalah. Meries dan Singh (2013) juga menjelaskan bahwa mengidentifikasi gaya-gaya yang bekerja sangat bermanfaat untuk membantu menyelesaikan masalah.

Berdasarkan hasil wawancara, siswa sulit memecahakan masalah pada hukum II Newton karena siswa masih belum memahami makna fisis dari persamaan hukum II Newton. Selain itu siswa hanya mengahafal rumus dan tidak terlatih mengidentifikasi gaya-gaya yang bekerja pada benda.

\subsection{Kesalahan Siswa dalam Memecahakan Masalah pada Hukum III Newton}

Butir soal yang digunakan untuk menunjukkan kemampuan pemecahan masalah pada masalah hukum III Newton disajikan pada Gambar 3. Terdiri dari 2 soal yaitu soal nomor 7 dan 8.

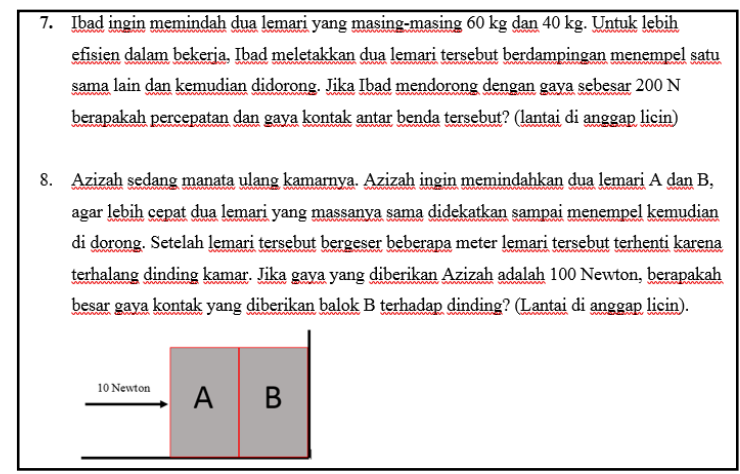

Gambar 3. Soal Pemecahan Masalah Hukum III Newton

Soal nomor 7 menunjukkan orang yang mendorong lemari dan kulkas yang saling ditempelkan dan masing-masing bermassa $60 \mathrm{~kg}$ dan $40 \mathrm{~kg}$. lemari didorong dengan gaya $200 \mathrm{~N}$. siswa diminta untuk menentukan gaya kontak antar benda tersebut. sebanyak 34 siswa menjawab dengan menuliskan besaranbesaran yang ada pada soal. Siwa yang menjawab demikian belum memahami hukum III Newton sehingga siswa tidak dapat menyelesaikan permasalahan. Sebanyak 2 siswa menjawab $\sum F=$ ma. Siswa yang menjawab 
demikian berpikir benda bergerak dengan percepatan a, sehingga siswa menggunakan hukum II Newton unutk menyelesaikan masalah. Sebanyak 24 siswa menjawab $\mathrm{Nab}=80 \mathrm{~N}$ dan Nba= $120 \mathrm{~N}$. Siswa yang menjawab demikian sudah memahami dan bisa menyelesaikan masalah hukum III Newton.

Soal nomor 8 menunjukkan orang yang mendorong dua lemari yang saling menempel dengan gaya sebesar $100 \mathrm{~N}$ hingga terhenti terhalang tembok. Siswa diminta untuk menentukan gaya kontak yang diberikan balok terhadap dinding. Sebanyak 28 siswa menjawab dengan menuliskan besaran yang ada pada soal. Siswa yang menjawab demikan belum memahami dan belum bisa menyelesaikan masalah hukum III Newton. Sebanyak 32 siswa menjawab besar gaya kontak yang diberikan balok B terhadap dinding adalah 100 N. Siswa yang menjawab demikian sudah memahami dan sudah bisa menyelesaikan masalah hukum III Newton.

Berdasarkan analisis data dapat diketahui bahwa siswa masih belum memahami hukum III Newton untuk menyelesaikan masalah tersebut. Siswa kebingungan ketika diminta untuk menetukan gaya kontak antar dua benda yang bersentuhan. Siswa hanya menghafal persamaan hukum III Newton. Siswa hanya menuliskan persamaan hukum III Newton yang berakibat siswa salah dalam menentukan strategi penyelesaian masalah. Kesalahan strategi adalah kesalahan yang terjadi jika siswa memilih jalan yang tidak sesuai sehingga tidak dapat menyelesaiakan permasalahan (Arti, 1994).

Berdasarkan hasil wawancara, siswa sulit memecahkan masalah pada hukum III Newton karena siswa hanya menghafal rumus hukum III Newton. Selain itu siswa hanya mengerjakan latihan soal. Hal tersebut berdampak siswa hanya bisa mengerjakan soal yang mirip dengan contoh soal.

\subsection{Kesalahan Siswa dalam Memecahakan Masalah pada Konsep Gaya Gesek}

Butir soal yang digunakan menunjukkan kemampuan pemecahan masalah pada konsep gaya gesek disajikan pada Gambar 4. Terdiri dari dua soal yaitu soal nomor 9 dan soal nomor 10.

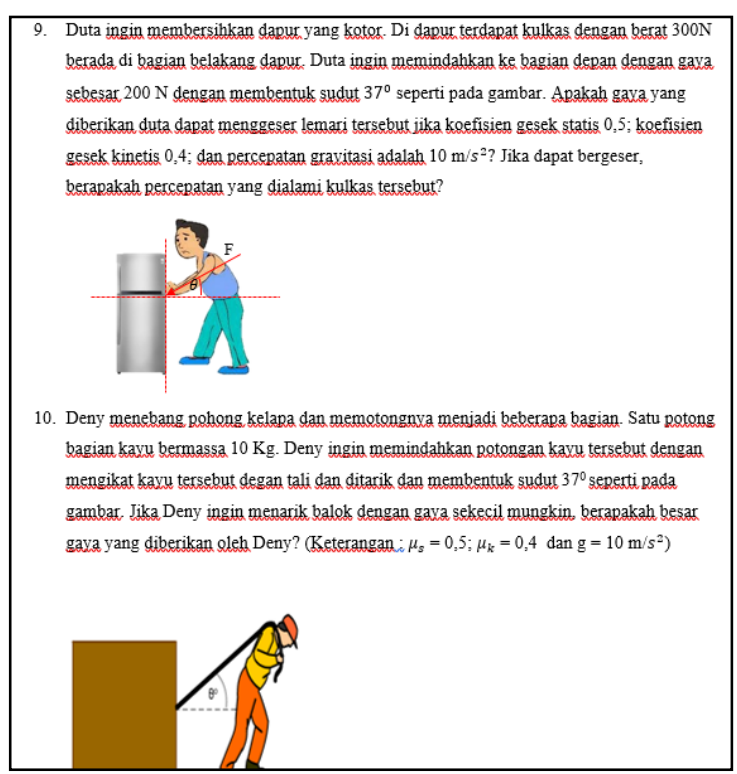

Gambar 4. Soal Pemecahan Masalah Gaya Gesek

Soal nomor 9 menunjukkan orang yang mendorong kulkas dengan berat $300 \mathrm{~N}$ dengan gaya sebesar $200 \mathrm{~N}$ dan membentuk sudut $\mathbf{3 7 ^ { 0 }}$ terhadap garis horizontal. Siswa diminta untuk menentukan apakah kulkas dapat bergerak atau tidak. Jika bergerak berapakah percepatan yang dialami kulkas. Sebanyak 33 siswa hanya menuliskan besaran yang ada pada soal. Siswa yang menjawab demikian belum memahami dan belum bisa menyelesaikan masalah pada konsep gaya gesek. Sebanyak 27 siswa menjawab lemari akan bergerak dengan alasan gaya yang diberikan (200 N) lebih besar dari gaya gesek (150 N). Siswa yang menjawab demikian sudah 
memahami konsep gaya gesek. Namun siswa masih belum bisa menguraikan gaya-gaya yang bekerja pada benda.

Soal nomor 9 menunjukkan orang yang menarik kayu yang bermassa $10 \mathrm{~kg}$ dengan membentuk sudut $\mathbf{3 7}^{\mathbf{0}}$ terhadap garis horizontal. Siswa diminta untuk menentukan besar gaya minimal yang dilakukan orang untuk menarik kayu tersebut. Sebanyak 43 siswa menjawab dengan menuliskan besaran yang ada pada soal. Siswa yang menjawab demikian belum memahami dan belum bisa menyelesaikan masalah pada konsep gaya gesek. Sebanyak 17 siswa menjawab $50 \mathrm{~N}$ namun jawaban ini salah. Siswa yang menjawab demikian sudah memahami konsep gaya gesek, namun belum bisa menguraikan gaya-gaya yang bekerja pada benda.

Berdasarkan analisis data dapat diketahui siswa masih belum bisa memahami konsep gaya gesek yang melandasari masalah pada gaya gesek. Pada soal nomor 20 siswa diminta menentukan gaya minimal yang diberikan untuk menarik balok. Hapir semua siswa salah menjawab soal. Siswa menghitung gaya gesek dengan cara megalikan koefisien gaya gesek dengan gaya normal. Karena siswa tidak menguraikan gaya-gaya yang bekerja menyebabkan siswa salah dalam menentukan besar gaya gesek yang bekerja pada benda. Seharusnya siswa menguraikan gaya pada komponen sumbu $x$ dan sumbu y seperti pada Gambar 5 .

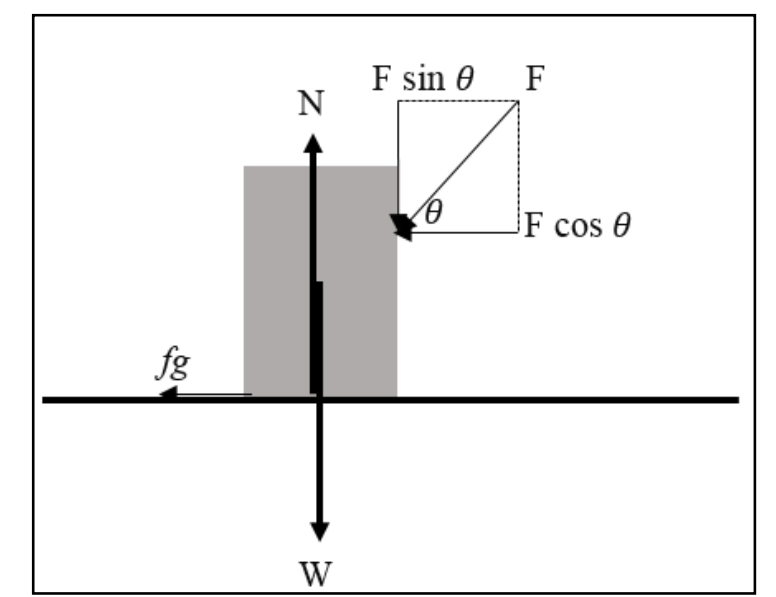

Gambar 5. Gambar Gaya-gaya yang Bekerja Pada Benda

Senada dengan pendapat Maries dan Singh (2013) menjelaskan bahwa menggabar garis-garis gaya yang bekerja pada benda dapat membantu siswa memecahakan masalah. Jadi sebelum menyelesaikan masalah, siswa harus menggambrakan gaya-gaya yang bekerja pada benda.

Berdasarkan hasil wawancara, siswa sulit dalam memecahkan masalah karena siswa tidak pernah menggambar gaya-gaya yang bekerja pada benda dan tidak pernah menguraikan gaya pada komponen sumbu $\mathrm{x}$ dan sumbu $\mathrm{y}$. Selain itu siswa hanya mengerjakan latihan soal sehingga siswa hanya bisa mengerjakan soal yang mirip dengan latihan soal.

\section{Simpulan}

Siswa mengalami banyak kesalahan dalam memecahkan masalah terkait hukum I Newton, hukum II Newton, hukum III Newton dan konsep gaya gesek. Kesalahan-kesalahan yang dilakukan diantaranya kesalahan konsep, kesalahan strategi dan tidak bisa menguraikan gaya-gaya yang bekerja pada benda. Hasil wawancara menunjukkan faktor-faktor yang menjadi penyebab kesalahan yang dilaukan siswa yaitu : (1) Siswa tidak memahami makan fisis persaman hukum Newton (2) Siswa hanya menghafal rumus (3) Siswa hanya mengerjakan latihan soal, yang berakibat siswa hanya bisa mengerjakan soal yang mirip contoh soal.

Selain itu perlu dilakukan penelitian lebih lanjut mengenai pemecahan masalah materi hukum Newton terutama dengan cara mengatasi dan mengurangi kesalahan-kesalahan yang dilakukan siswa ketika memecahakan masalah hukum Newton. Siswa diajak praktikum untuk lebih memahami hukum Newton dan dilatih membangun konsepnya sendiri. Salah satu caranya dengan pembelajran yang melibatkan siswa ikut 
serta dalam pemecahan masalah. Karena pemecahan masalah masih sulit dilakukan untuk tingkat SMA maka perlu diberikan bantuan hingga siswa dapat menyelesaikan masalahnya secara mendiri.

\section{Daftar Rujukan}

Astrina, S., Sahala, S., \& Oktavianty, E. (2014). Remediasi Miskonsepsi Siswa pada Materi Hukum Newton Menggunakan Jigsaw Berbantuan Booklet Kelas Viii Smp. Jurnal Pendidikan dan Pembelajaran, 3(1).

Care, E., Scoular, C., \& Griffin, P. (2016). Assessment of Collaborative Problem Solving in Education Environments. Applied Measurement in Education, 29(4), 250-264. https://doi.org/10.1080/08957347.2016.1209204

Ding, L., Reay, N., Lee, A., \& Bao, L. (2011). Exploring the role of conceptual scaffolding in solving synthesis problems. Physical Review Special Topics - Physics Education Research, 7(2). https://doi.org/10.1103/PhysRevSTPER.7.020109

Docktor, J. L., Strand, N. E., Mestre, J. P., \& Ross, B. H. (2015). Conceptual problem solving in high school physics. Physical Review Special Topics - Physics Education Research, 11(2). https://doi.org/10.1103/PhysRevSTPER.11.020106

Hu, D., \& Sanjay Rebello, N. (2013). Characterizing student use of differential resources in physics integration problems. In AIP Conference Proceedings(Vol. 1513, pp. 186-189). American Institute of Physics Inc. https://doi.org/10.1063/1.4789683

Ibrahim, B., \& Rebello, N. S. (2012). Representational task formats and problem solving strategies in kinematics and work. Physical Review Special Topics - Physics Education Research, 8(1). https://doi.org/10.1103/PhysRevSTPER.8.010126Kim, E., \& Pak, S.-J. (2002). Students do not overcome conceptual difficulties after solving 1000 traditional problems. American Journal of Physics, 70(7), 759-765. https://doi.org/10.1119/1.1484151

Kim, E., \& Pak, S.-J. (2002). Students do not overcome conceptual difficulties after solving 1000 traditional problems. American Journal of Physics, 70(7), 759-765. https://doi.org/10.1119/1.1484151

Knight, R. D., \& Knight, R. (2004). Physics for Scientists and Engineers: A Strategic Approach with Modern Physics with Mastering Physics. Benjamin Cummings.

Kuo, E., Hull, M. M., Gupta, A., \& Elby, A. (2013). How students blend conceptual and formal mathematical reasoning in solving physics problems. Science Education, 97(1), 32-57. https://doi.org/10.1002/sce.21043

Lin, P. C., Hou, H. T., Wu, S. Y., \& Chang, K. E. (2014). Exploring college students' cognitive processing patterns during a collaborative problem-solving teaching activity integrating Facebook discussion and simulation tools. Internet and Higher Education, 22, 51-56.

https://doi.org/10.1016/j.iheduc.2014.05.001

Lin, T. J., Duh, H. B. L., Li, N., Wang, H. Y., \& Tsai, C. C. (2013). An investigation of learners' collaborative knowledge construction performances and behavior patterns in an augmented reality simulation system. Computers and Education, 68, 314-321. https://doi.org/10.1016/j.compedu.2013.05.011

Malichatin, H. (2013). Pengembangan materi subjek bagi mahasiswa calon guru fisika. Journal of Innovative Science Education, 2(1).

Maries, A., \& Singh, C. (2013). To use or not to use diagrams: The effect of drawing a diagram in solving introductory physics problems. In AIP Conference Proceedings(Vol. 1513, pp. 282-285). American Institute of Physics Inc. https://doi.org/10.1063/1.4789707

Nurcahyo, A. W. (2017). Analisis Kemampuan Pemecahan Masalah Hukum Newton Tentang Gerak Pada Mahasiswa Pendidikan Fisika Universitas Jember Melalui Pembelajaran Cooperative Problem Solving. DISERTASI dan TESIS Program Pascasarjana UM.

Planinic, M., Boone, W. J., Krsnik, R., \& Beilfuss, M. L. (2006). Exploring alternative conceptions from newtonian dynamics and simple DC circuits: Links between item difficulty and item confidence. Journal of Research in Science Teaching, 43(2), 150-171. https://doi.org/10.1002/tea.20101

Radovanović, J., \& Sliško, J. (2013). Applying a predict-observe-explain sequence in teaching of buoyant force. Physics Education, 48(1), 28-34. https://doi.org/10.1088/0031-9120/48/1/28

Serway, R.A. and Jewett, J.W. 2010. Physisc for Scientist and Engineers with Modern Physics. 8th Edition. California: Thomson Brooks/Cole. 
Shiha, S. N. (2014). Pengembangan Alat Peraga Percepatan Benda Untuk Menunjang Pembelajaran Fisika Pada Materi Hukum Newton Tentang Gerak. Inovasi Pendidikan Fisika, 3(2).

Sriati, A. (1994). Kesulitan Belajar Matematika pada Siswa SMA (Pengkajian Diagnosa). Jurnal Kependidikan Jogjakarta.

SUSIANA, N. (2017). Analisis Kemampuan Pemecahan Masalah Siswa SMA Kelas X melalui Model Interactive Demonstration dengan Thinking Maps pada materi Hukum Newton. DISERTASI dan TESIS Program Pascasarjana UM.

Zewdie, Z. M. (2014). An investigation of students' approaches to problem solving in physics courses. International Journal of Chemical and Natural Science, 2(1), 77-89. 